Vickers, L (2011) The expanded public sector duty: Age, religion and sexual orientation.

Vickers, L (2011) The expanded public sector duty: Age, religion and sexual orientation. International Journal of Discrimination and the Law, 11 (1-2). pp. 43-58.

This version is available https://radar.brookes.ac.uk/radar/items/9555abb2-45f6-79ad-692b-394493d9f8ab/1/

Available on RADAR: June 2013

Copyright ( $)$ and Moral Rights are retained by the author(s) and/ or other copyright owners. A copy can be downloaded for personal non-commercial research or study, without prior permission or charge. This item cannot be reproduced or quoted extensively from without first obtaining permission in writing from the copyright holder(s). The content must not be changed in any way or sold commercially in any format or medium without the formal permission of the copyright holders.

This document is the postprint version of the journal article. Some differences between the published version and this version may remain and you are advised to consult the published version if you wish to cite from it. 


\title{
The Expanded Public Sector Duty: Age, Religion And Sexual Orientation
}

\author{
Professor Lucy Vickers \\ Oxford Brookes University
}

The Equality Act 2010 is largely a consolidating statute, bringing together a raft of equality measures enacted over the last 40 years. Along side this consolidation, the Act also introduces some new measures, including the creation of new public sector equality duties to cover religion and belief, age, sexual orientation and maternity and pregnancy. Similar duties were already in place generally in the public sector with regard to race, gender and disability, ${ }^{1}$ and with respect to other grounds for Greater London, as discussed in Lulham's contribution to this volume. The expansion of the public sector duties are best viewed as an attempt to harmonise or 'level up' the protection available to the newer equality grounds in the consolidating 2010 Act. However, as will be illustrated below, this extension of the equality duty to new grounds may be somewhat problematic, and may illustrate some of the underlying tensions in current equality law.

\section{Overview of the new equality duty}

Most of the provisions of the Equality Act 2010 came into force in October 2010 , but the newly extended public sector equality duty is due to come into effect in April 2011. The duty is contained in s 149 of the Act and provides:

(1) A public authority must, in the exercise of its functions, have due regard to the need to-

(a) eliminate discrimination, harassment, victimisation and any other conduct that is prohibited by or under this Act;

\footnotetext{
${ }^{1}$ Race Relations (Amendment) Act 2000, Disability Discrimination Act 2005, Equality Act 2006, amending the Sex Discrimination Act 1975. Public sector duties had already been introduced in Northern Ireland, Wales.
} 
(b) advance equality of opportunity between persons who share a relevant protected characteristic and persons who do not share it;

(c) foster good relations between persons who share a relevant protected characteristic and persons who do not share it....

(3) Having due regard to the need to advance equality of opportunity....involves having due regard, in particular, to the need to(c) encourage persons who share a relevant protected characteristic to participate in public life or in any other activity in which participation by such persons is disproportionately low.

The duty applies to the protected characteristics of age, disability, gender reassignment, pregnancy and maternity, race, religion or belief, sex, and sexual orientation. In addition, the Equality Act 2010 introduces the concept of combined discrimination with respect to dual characteristics, so that discrimination is protected when it is the result of a combination of two characteristics.

Exactly what is required to comply with the new duty is not yet clear, however some guidance can be found from the experience with the earlier public sector duties on grounds of race, gender and disability. The duties are enforced via judicial review proceedings. Where cases have come before the courts they have involved issues such as a failure to have due regard of race equality in making planning decisions, ${ }^{2}$ failure to have due regard to the needs of people with disabilities in making decisions on closing post offices, and challenges to the funding for domestic violence support. ${ }^{3}$ The scope of the duties to challenge government policy making can be seen in the attempt of the Fawcett Society in the summer of 2010 to challenge the Coalition Government's economic plans and budget proposals via judicial review

\footnotetext{
${ }^{2}$ See for example $R$ (on the application of Janet Harris) v Haringey London Borough Council and others [2010] EWCA Civ 703

${ }^{3} R$ (on the application of (1) Kaur (2) Shah (Claimants) $v$ Ealing London Borough Council (Defendant) \& Equality \& Human Rights Commission (Intervenor)_ [2008] EWHC 2062 (Admin)
} 
proceedings, for failing to take into account its gender duty or undertake an equality impact assessment before making the plans. ${ }^{4}$

Despite some successful claims, litigated cases relating to the previously existing equality duties are few. Perhaps a different measure of the success of the public sector equality duties is the development of a culture of mainstreaming race, gender and disability equality measures in most public sector organisations. (Lulham 2011, Stewart 2011). Organisations have largely complied, at least to the extent that they have introduced equality training for staff, have introduced equality policies, and have started to introduce equality requirements into the procurement process. Indeed the 2004 Workplace Employment Relations Survey found an increase in the proportion of workplaces with formal written equal opportunities policies since 1998. By 2004, 73 per cent of workplaces had a formal policy in place. Levels were even higher in workplaces with at least 100 employees (96\%) and in the public sector (98\%). Although the majority of policies covered the grounds of sex, race and disability, many also already covered the new grounds. (Kersley et al 2004).

Of course, it may well be the case that the introduction of such processes merely amount to a bureaucratic, 'tick-box' response, with a focus on compliance, rather than reflecting a real commitment on the part of these bodies to achieving substantive equality outcomes (O'Cinneide, 2006). There is some evidence that this is the case (see further Fairness and Freedom Report 2007, and Kersley et al 2004) and it is certainly not argued here that the introduction of the public sector duties can create a completely new workplace culture, and alone eradicate inequality. However, the examples given elsewhere in this volume suggest that there have been positive outcomes in some cases, for example in increased supplier diversity in some areas of the public sector, and as part of a broad approach to promoting equality, the public sector duties would seem to have a significant part to play.

\footnotetext{
${ }^{4}$ http://www.fawcettsociety.org.uk/index.asp?PagelD=1177 (accessed 15/10/10)
} 


\section{The Potential Impact of the Expanded Public Sector Duty}

Many employers who have implemented the public sector duty with respect to sex, disability and race have taken a broad approach to equality and have already included the new grounds of age, sexual orientation and religion and belief. However, where this has not already occurred, the duty can be expected to introduce some changes to current practice. Suggestions from the explanatory notes to the Equality Act 2010 as to how the duty may be implemented contain the following:

The duty could lead a local authority to review its use of internet-only access to council services; or focus "Introduction to Information Technology" adult learning courses on older people, with the aim of advancing equality of opportunity, in particular meeting different needs, for older people.

The duty could lead a school to review its anti-bullying strategy to ensure that it addresses the issue of homophobic bullying, with the aim of fostering good relations, and in particular tackling prejudice against gay and lesbian people.

The duty could lead a local authority to introduce measures to facilitate understanding and conciliation between Sunni and Shi'a Muslims living in a particular area, with the aim of fostering good relations between people of different religious beliefs.

Although theses examples relate to single grounds, those implementing the equality duties will also need to take into account the phenomenon of combined discrimination when formulating equality policies, to ensure that the needs for example of minority ethnic women, or elderly gay men are adequately addressed. 
The suggestions contained in the guidance available on the extension of the public sector duty appear to be sensible suggestions aimed at tackling clear examples of inequality, and to that extent, they do not appear problematic. However, further thought about how the equality duty may apply to the new equality grounds may give rise to some concern, as set out below.

\section{New Grounds for Concern?}

\section{Religion:}

A number of concerns can be raised about the extension of the public sector duty to religion (Lester and Uccellari, 2008; Vickers, 2011). For example, a preliminary concern is that the term 'religion and belief' is not defined clearly in the legislation. ${ }^{5}$ This leaves an element of uncertainty at the heart of the protection and may well leave some public authorities unclear about the scope of the new duty.

Additional concern about the lack of definition may be raised by the case of Nicholson $v$ Grainger PLC ${ }^{6}$ in which the EAT held that beliefs about climate change could amount to a protected belief. If this definition is carried across from the employment context to the public sector duty context, it could mean that attempts to promote a green agenda could come within the public sector duty, meaning that public authorities would need to take steps to foster good relations between those who share the belief, and those who do not. This could possibly provide a publicly funded boost to those who do not support the public sector 'green' agenda.

Even apart from the definitional problem for the scope of the duty, further more fundamental concerns arise with regard to the religion and belief duty. This is because the 'religion and belief' ground includes within it those with a religion and belief and those without. This means that it may be difficult for a public authority to demonstrate that it is treating equally both those with

\footnotetext{
${ }^{5}$ Religion means 'any religion' and belief means 'any religious or philosophical belief'. Equality Act 2010 s 10.

${ }^{6}$ [2010] I.C.R. 360
} 
religion, and those without. The problem arises because the two groups' interests are likely to be in conflict; this is because the promotion of understanding between religious groups by public authorities is unlikely ever to be compatible with providing equality for those who do not want to see religion in public life at all. Protection is included for belief as well as religion, and covers those without any religion or belief at all, yet promoting good relations between these groups is likely to be more disadvantageous to those who wish to see a secular public sphere than to others, because the very fact that the issue is being raised at all will be seen as disadvantageous to them. Yet the aim of the public sector duty is to treat these different groups equally. In this regard, these two aims appear irreconcilable.

A further area of difficulty with regard to the religion and belief duty is that many religion and belief groups are not themselves supportive of equality (McColgan, 2009; Okin, 1998) For example, some religious groups are not supportive of equality on grounds of gender, sexual orientation or disability. This can mean that in attempting to foster good relations between those with a religion or belief and those without, a public authority could appear to lend support to groups which themselves do not adhere to the concept of equality as it is commonly understood, or at least legislative conceptualised.

\section{Age}

The measures envisaged by the guidance available on the public sector duties suggests that the concern is with ensuring that public authorities are able, for example, to target poverty in older people, or to direct employment measures to help young people into employment. Of course, such aims are perfectly laudable, but raise a number of background questions about why we prohibit age discrimination, which need to be addressed if the public sector duty is to be appropriately implemented.

One obvious issue relating to age equality is that it can be difficult to pin down exactly which ages are the disadvantaged ones. It is usually assumed that 
older people suffer disadvantage, although at what age this starts is unclear. Certainly poverty among those of pensionable age is common (Bardasi and Jenkins, 2002) as is discrimination against older workers, viewed as too old to learn new skills and not worth investment in terms of promotion or provision of training. However, the extent of disadvantage can differ according to occupational group, and determining when the disadvantage starts can also vary, with workers over 40 , over 50 or over 60 being variously affected (Manfredi, 2008). In addition, there is evidence of disadvantage for younger people, with difficulties in accessing work and housing, and assumptions that young workers are not capable of taking responsibility or will not be taken seriously by clients (Manfredi, 2008). It is thus right, if age is to be protected, that the Equality Act 2010 should protect age, and not old age.

However the fact that there are lots of different types of disadvantage that arise at different ages can make it a difficult ground to protect. This is even more the case when the public sector duty is considered. The fact that both old and young are protected is not a problem with respect to the prohibition of age discrimination: a person can be treated less favourably because they are either older or younger than a chosen comparator. However, when it comes to taking steps to promote equality, or to foster good relations between groups, the issue of identifying which groups are covered may be more problematic, as both older and younger workers can face different inequalities. Indeed, it is arguable that the interests of different age groups conflict with each other; the desire for older workers to continue to work beyond the traditional retirement age could conflict with the policy of helping younger workers access employment. Such an argument may be flawed at a macro level, as the job market does not work on a strict 'one in, one out' basis, but it may have some validity at a more local or sectoral level (Fredman 2003 and Manfredi and Vickers 2009).

Moreover, a more fundamental difficulty arises with respect to age discrimination, and this is the fact that age is a characteristic which all people share but which is ever changing: all start young, and aspire to become old. 
This means that there is less fundamental agreement about why and to what extent age should be protected.

In terms of the reasons for including age as a protected characteristic, the arguments are based on two models: first, a dignity model, where the rationale is that treating people less favourably based on age infringes the fundamental equality principle, as it is based on stereotyped assumptions about age and amounts to an affront to individual dignity. The second model is more pragmatic and economic: employers need to tap into the resource of older and younger workers who may have much to offer the workplace. Failure to do so means missing talent based on stereotypical assumptions. Moreover, there is arguably an economic case for employing older people to address the demographic changes resulting in fewer younger people being available to work; although the strength of this case may be questioned in an era of under employment. A further pragmatic case for allowing workers to work into older age can be found in the decrease in pension levels, and increase in pension age.

Despite these clear arguments in favour of protecting age, there remain powerful arguments suggesting that it is a characteristic which is different from the others which are protected in the Equality Act 2010, so that although there may be reasons to protect against direct or indirect discrimination, there is no need to offer the additional protection for the ground provided by the public sector duty. For example, the 'fair innings' argument, identified (but not supported) by Fredman (Fredman, 2003) would suggest that different ages are equal, because over a lifetime everyone has a time of being young and a time of being old. Thus older people have had a chance to enjoy the benefits and disadvantages of youth, and the young will, in turn, face the advantages and disadvantages of age. The argument is therefore that distinctions based on age are not unfair, as we all move from advantage to disadvantage at different stages of our lives. Another version of this argument is that the advantages and disadvantages of age and youth cancel each other out over a life time, meaning there is no need for special protection. An alternative argument against protecting age as a characteristic is that the market can be 
trusted to overcome some of the difficulties: for example, if an aging population will force employers to recruit older workers, to fill a skills gap.

Each of these arguments can be countered; for example the 'fair innings' argument can be seen to be flawed as it is based on an assumption that everyone has had fair opportunities during a working life, when we know that many do not have such opportunities (Manfredi and Vickers, 2009). Full discussion of the merits of including age as a protected characteristic is beyond the scope of this article, but it is important is to acknowledge that the status of age as a protected characteristic is disputed; and that this dispute is particularly significant in the context of the public sector duty.

For example, if the reason for protecting age as a characteristic is that there is a correlation between older age and poverty, it remains unclear why the focus should be on age, rather than poverty per se; and if a problem is identified for young people getting started on the career ladder, again it is unclear why that concern should be targeted at young people. If long term unemployment is a problem, it is unclear why it is worse if one is younger. Taking the example from the government's explanatory notes, it is unclear why an access to information technology should be focussed on older people, if there are also younger people who are IT illiterate. In effect, the difficulty is that although age can be a reasonably reliable proxy for some forms of disadvantage, it is not clear whether it is more than this. As a proxy for disadvantage, the characteristic of age may warrant protection from discrimination. However, it is not clear whether this justifies the extension of the public sector duty to age, thereby not only addressing disadvantage, but also encouraging the wider promotion of equality, such as the fostering of good relations between age groups.

\section{Sexual Orientation:}

Again, as with age, there is clear evidence of disadvantage that can be suffered by gay and lesbian people. Examples given by Stonewall include the widespread harassment of LGBT people, young LGBT people facing housing problems caused by leaving home to escape homophobia; assumptions being 
made in care provision for older LGBT people that everyone is heterosexual; and LGBT people being forced to be open about their sexuality in order to report a crime to the police or anti-social behaviour to their landlords. Clearly an awareness of these issues on the part of public authorities, and the expansion of the public sector duty to this ground should lead to better planning of public services, so that they better meet the needs of LGBT people.

However, as with the expansion of the duty to other grounds, care needs to be taken in formulating how the equality duty should be implemented. It is clearly laudable to attempt to end less favourable treatment on grounds of sexual orientation, but it is less clear why, for example, this requires public authorities to 'encourage persons who share a relevant protected characteristic to participate in public life or in any other activity in which participation by such persons is disproportionately low.' Of course, it is necessary to ensure that the interests of specific groups are addressed in the democratic process; but it does not necessarily lead from this that a person has to share the characteristic in order to do this. If this is the case, it may lead to some difficult conclusions, particularly for some of the new grounds. For example, given the range of religions and beliefs (and non-belief) that could possibly be represented, how would fair representation be assured? Can atheists represent agnostics, as both share the characteristic of not having a religious belief? Would a lesbian women be assumed to represent gay men? And what age would a person have to be in order to ensure fair participation on grounds of age?

An assumption that diversity of participation in public life is a good of itself thus creates an inherent problem in terms of ensuring representativeness of different groups, but it also reflects a more fundamental tension between the equality and diversity as policy aims. In effect there is a tension between protecting equality on the basis that people are fundamentally the same in terms of ability; and protecting equality on the basis that individuals bring unique qualities to the table, according to their different characteristics, and that these should be recognised. Although this latter thinking values 
difference, on the basis that each group has unique skills, the danger of such thinking is that it endorses the very stereotypical assumptions that have long been fought against, such as assumptions that quick thinking is a unique and valued feature of youth, or that wisdom is a unique and equally valued older person's trait.

This fundamental tension within equality law is made more visible when considering the public sector equality duties. In order to consider whether these tensions can be resolved in the context of the new grounds, therefore, it will be helpful to consider briefly the current debates regarding the various meanings of equality.

\section{The Various Meanings of Equality}

The overarching aim of the public sector equality duties is to promote equality between different groups. The difficulty with such an aim is, however, that equality has a range of meanings, and so determining what it might mean to promote equality in this context is problematic (McCrudden, 2005). There has been extensive academic debate about the meaning and purposes of equality ${ }^{7}$ and it will only be possible to give a brief outline of that debate here.

The first and most obvious meaning for equality is formal or symmetrical equality, in which like cases are treated alike. The shortcomings of this approach are well recognised (that it can be difficult to tell when likes are indeed alike; ${ }^{8}$ and that a formal approach to equality can lad to levelling down of treatment so that everyone is treated 'equally badly'). ${ }^{9}$ Clearly such a formal approach to equality does not provide support for the public sector duty concept: formal equality requires only that like be treated alike, not that

\footnotetext{
${ }^{7}$ See for example, O'Cinneide, 'Fumbling Towards Coherence: The Slow Evolution of Equality and Anti-Discrimination Law in Britain' (2006) NILQ 57, C Barnard and B Hepple, 'Substantive Equality' (2000) 59 CLJ 562, S Fredman, Discrimination Law (Oxford, OUP, 2002), Hepple, 'The Aims of Equality Law' in O'Cinneide and Holder (eds) Current Legal Problems (2008, OUP, Oxford). See also N Fraser, 'Rethinking Recognition' (2000) 3 New Left Review 107, and C Taylor, Multiculturalism and 'The Politics of Recognition (1992, Princeton University Press, Princeton).

${ }^{8}$ See P Westen, 'The Empty Idea of Equality' (1982) 95 Harv. L.R. 537

${ }^{9}$ See for example, C Barnard and B Hepple, 'Substantive Equality' (2000) 59 CLJ 562 and S Fredman, Discrimination Law (Oxford, OUP, 2002).
} 
positive steps should be taken to promote equality or good relations between groups.

A more substantive view of equality has to be taken if the concept is to be used to justify and help define the scope of the public sector duty, a view which allows the relative disadvantage of some groups in contrast to others to be taken into account. At least three more substantive models of equality can be identified in the literature. First, a model of equality which focuses on the link between equality and individual dignity and identity; second, a model which focuses on disadvantage and redistribution; ${ }^{10}$ and third, a model based on equality as a means of addressing social exclusion and promoting participation. ${ }^{11}$ These broader concepts of equality will be explored a little further here as they may help develop a framework through which to assess the public sector equality duties and suitability of extending them to the new grounds of religion and belief, age and sexual orientation.

\section{Equality as dignity}

One way of understanding the concept of equality is to view it as a reflection of the Kantian concept that humans should be treated as ends rather than means, ${ }^{12}$ because they are all of intrinsic and incomparable worth, and all share an essential dignity as human beings. As stated in the Universal Declaration of Human Rights: 'All human beings are born free and equal in dignity and rights'. ${ }^{13}$ As all are equal in their humanity and moral worth, equality is clearly closely linked to this concept of dignity.

The idea of human dignity leads to a broader concept of equality than that based on formal equality, because it focuses on the autonomy and dignity of individuals, rather than on achieving the same treatment. It allows for

\footnotetext{
${ }^{10}$ See C Barnard and B Hepple, 'Substantive Equality' (2000) 59 CLJ 562.

${ }^{11} \mathrm{H}$ Collins 'Discrimination, Equality and Social Inclusion' (2003) 66 MLR 16, S Fredman, The Future of Equality In Britain, EOC, Working Paper Series No. 5, (London, Equal Opportunities Commission 2002) 11, N Fraser, 'Rethinking Recognition' (2000) 3 New Left Review 107.

${ }^{12}$ E Kant, The Moral Law: Kant's Groundwork of the Metaphysics of Morals (trans HJ Paton) London, Hutchinson 1963).

${ }^{13}$ Art 1. Dignity also features in the preamble to the United Nations Charter, and the preambles of the ICCPR and ICESCR.
} 
accommodation of difference, ${ }^{14}$ enabling special treatment to be afforded to some to enable them fully to participate in society, without having to afford such treatment to all. It also creates room to provide broader 'recognition' ${ }^{15}$ for differences rather than mere tolerance. This is the idea is that inequality arises not just in socio-economic terms, but in more cultural and symbolic terms too, so that people will only be fully equal if they are enabled to develop a sense of personal identity and to have that identity recognised and respected by society. ${ }^{16}$ This broader notion of equality based on dignity and recognition provides good support for the public duty agenda. It acknowledges that full equality will only be achieved when individuals enjoy social and cultural equality, which will be enhanced by the actions of public authorities in promoting equality and fostering good relations between groups.

However, basing the public duty on this understanding of equality also gives rise to some reservations, as indicated above. A focus on dignity and recognition involves an inherent tension between valuing the universal equality of different people, and valuing their unique identities, as illustrated above with respect to the danger of endorsing stereotypes about the typical qualities that each group may bring to an organisation (strategic thinking, nurturing, wisdom etc.). Such thinking can lead to the entrenching of difference rather than overcoming it.

This could be a particular problem when considered in the context of the positive duty, which anticipates the promotion of particular group interests by positive action, such as special service provision to particular groups. As suggested above using the government's own example, it is difficult to see what it is about age, in terms of dignity or recognition, which would justify the creation of special IT classes for older people.

\footnotetext{
${ }^{14}$ See Moon and Allen, 'Dignity Discourse In Discrimination Law: A Better Route To Equality' (2006) EHRLR 610.

${ }^{5}$ See N Fraser, Rethinking Recognition (2000) 3 New Left Review 107 and C Taylor, Multiculturalism and 'The Politics of Recognition' (1992, Princeton University Press, Princeton).

${ }^{16} \mathrm{~N}$ Fraser, From Redistribution to Recognition? Dilemmas of Justice in a 'Post-Socialist' Age (1995) New Left Review 1/212 68
} 
Moreover, even where recognition may at first appear to give rise to a good underpinning for the duty (take for example the government's example of measures to facilitate understanding and conciliation between Sunni and Shi'a Muslims) some problems remain. There remains the danger that such an action could be viewed providing some official endorsement of religion, although not of the particular religion itself, which may be criticised by those who believe that religion should be kept out of the public sphere. An argument based on the need to enhance the dignity of different groups is unable to meet this criticism. Thus dignity and recognition as underpinning concepts of equality may not provide a sufficient basis for extending the public sector duty to the new grounds.

\section{Equality and disadvantage}

These difficulties with the concept of equality are significantly lessened if equality is viewed instead as concerned to overcome disadvantage. Here the concern is not so much with enhancing and upholding various grounds of individual identity, but with using the equality grounds to identify disadvantage. This approach sees the wrong of discrimination as being in the way it causes disadvantage, rather than in its lack of recognition of different identities

In this equality model, the equality grounds are used more explicitly as proxies for disadvantage. Where this is the case, the problems identified with equality understood as dignity fall away. Returning to the examples used above, instead of being concerned that we are unclear why we are concerned with older person's IT skills over those of a different age, the answer is that we are not: we are concerned with lack of IT skills, and target interventions to where they are likely to have the greatest hit rate, here with older people. If a different group were to be identified as lacking IT skills, (say a religious minority) under such an understanding, the resource of IT skills teaching would quite happily be switched to the newly identified disadvantaged group. Equally, if unemployment is a particular problem for those under 30 , then we should target employment interventions to that age group. This is not because the problem it is worse to be unemployed at 25 than at 35 in terms of personal 
dignity, but because there are more younger people unemployed. If the age range shifts, then the interventions can shift. Moreover, to target interventions to particular religious groups would not involve giving any state endorsement to the religion, but would be more concerned to target the service where the need for the service is greatest.

The benefit of this approach is that it does not provide value to the characteristics that are protected. Thus religion is not endorsed, and public authorities would not have to ensure even treatment of every religious group. Equally, it is unnecessary to identify why age is being protected; it can merely be accepted that different disadvantages can be associated with different ages.

However, there remains a problem with using disadvantage as the underlying concept of equality and that is that the different equality grounds are not always reliable proxies for disadvantage. First, disadvantage is subject to varied definitions, including economic disadvantage, educational disadvantage, and disadvantage in terms of access to healthcare, and it may not always be easy to find out if those with the particular protected characteristic suffer the particular disadvantage at stake in any given situation. Moreover, multiple identities mean again that the grounds as proxies for disadvantage may not be very reliable. For example, there may be very great differences in disadvantage between young Muslim men and older Muslim women; or between white gay men and straight black men, making it hard to identify where disadvantage lies. Identifying disadvantage is therefore a constant challenge for an equality duty based on the concept of disadvantage and there is a constant danger that services targeted to 'disadvantaged' groups will be colonised by the more advantaged members of the group (Barmes, 2009).

The difficulty with correctly identifying where disadvantage lies is a significant reservation on the reliance on disadvantage to justify the expansion of the public sector duty. Taking age, for example, although there is a clear correlation of age with poverty, there is also strong evidence of some older 
people having enjoyed better economic conditions than the generations before enjoyed or those coming after them are likely to enjoy (The Guardian, $6 / 11 / 09$ ). Equally, although there is evidence of lack of 'recognition' equality for LGBT people, evidence of economic hardship may be less clear. On the other hand, disadvantage should not be understood only as an economic issue, and the hardship suffered in the context of housing and elder care for example is identifiable as a particular disadvantage suffered by the LGBT community, apart from the inequality involved in terms of dignity and recognition. The difficulty with identifying the ways in which disadvantage arises, and how it may vary within groups sharing protected characteristics illustrates the practical problems that are likely to arise if disadvantage only is used as the theoretical basis for the expanded public sector duties.

To an extent, the difficulties identified with basing the public sector duty on the concept of disadvantage would be overcome if the focus on named grounds of disadvantage was removed. Instead, a more generalised duty to address disadvantage would be preferable. Indeed, it would seem that rather than introduce the new expanded public sector duty, it would have been preferable to have brought into force the duty in section 1 of the Equality Act 2010, the public sector duty regarding socio-economic inequalities which provides that

a [public] authority must, when making decisions of a strategic nature about how to exercise its functions, have due regard to the desirability of exercising them in a way that is designed to reduce the inequalities of outcome which result from socio-economic disadvantage.

Such a duty avoids the problems identified above with the named ground public sector duty. For example, it would avoid the problem of giving value to the characteristic (such as seeming to endorse a religious group), and would also address the danger of advantaged members of a group receiving an undeserved benefit (such as wealthy older people being able to gain free IT classes). 
However, it is now clear that this more general socio-economic duty will not be implemented, and so the named ground duty will be the mechanism by which the public sector duty will be expanded. It is therefore worth considering further whether there is a concept of equality that could be used to guide its implementation to avoid some of the pitfalls identified above.

\section{Equality and inclusion}

A third model of equality is that based on the idea of inclusion. This concept embraces both recognition and disadvantage, with equality seen as a means of breaching the cycle of disadvantage associated with out-groups as well as promoting respect for the equal dignity of all and redressing stigma and stereotyping, affirming community identities and facilitating full participation in society (Fredman, 2002). In effect, the argument is that minority groups need to be encouraged to participate in civic life, so that their voice within the community can become stronger, leading to an end to their marginalisation and disadvantage and at the same time enhancing their dignity (Collins, 2003). Thus recognition and an end of disadvantage are seen not as ends in themselves, but as ways to achieve a more equal society in terms of economic distribution and social harmony.

A focus on social inclusion provides a basis for more positive action in order to achieve equality and so provides perhaps the best theoretical underpinning for the public sector duty. It provides a good fit with the proactive approach of the public sector duties which seek to put thinking about equality at the heart of public authority decision making: indeed the idea of equality as inclusion and participation is included in section 149(3)(c) Equality Act 2010 of the duty to have due regard to the need 'to encourage persons who share a relevant protected characteristic to participate in public life or in any other activity in which participation by such persons is disproportionately low.'

A number of difficulties were identified above with the expansion of the public sector duties to the new grounds. In part these were identified as caused by a tension between using equality law to embrace and celebrate difference and using equality law to overcome difference. The brief exploration of various 
meanings of equality, above, has helped to clarify how this tension might be at least partially resolved in a way which may meet the objections set to the expansion of the duty.

If equality is understood to involve better participation and inclusion in society, then some of the tension between celebrating difference and eradicating it can be resolved. It recognises that difference does not necessarily need eradicating, only the disadvantage that it can generate. It also means that greater participation of otherwise excluded groups can ensure that their different characteristics are not ignored (that is, they receive adequate recognition) while working towards the eradication of disadvantage.

Moreover, an approach based on inclusion can help to overcome some of the problems identified with the different new grounds. It was suggested above that the difficulty with disadvantage can be in identifying where and when it arises for the different group; and for recognition or dignity, problems arose in particular with religion where the approach could be viewed as endorsing the views themselves. A focus on inclusion should enable the voices of different groups to be heard as public authorities plan service provision, without simultaneously suggesting that the public authority values any particular group over another.

\section{Conclusion}

A number of concerns have been identified with regard to the extension of the public sector duty to new grounds in the Equality Act 2010. These have included the danger of public authorities seeming to endorse religious views through the implementation of policies designed to celebrate the different communities which they represent, concerns about how to correctly identify age groups covered by the age duty, and about correctly defining the parameters of the duty with regard to LGBT people.

It was suggested above that the implementation of the more generic public sector duty regarding socio-economic disadvantage may have overcome 
many of these difficulties, rather than a focus on named equality grounds. However, the general socio-economic disadvantage duty will not be brought into force, and the section 149 duty is expected to be implemented in April 2011, so it is more important now to consider how best to put it into the new duties into effect, so as to minimise the potential problems.

To this end, a model of equality has been identified which provides the clear theoretical underpinning for the duty. It is thus suggested that those implementing and designing the public sector duties should have a clear agenda to tackle disadvantage, and to promote inclusion and participation in society by all. Action can be targeted on the basis of a named equality ground, such as religion or belief, age or sexual orientation where it is necessary to do so in order to achieve that aim. This allows public authorities more accurately to target their attention to areas of need. The focus does not need to be solely on economic disadvantage. Instead if the duty is based on inclusion, public authorities are able to recognise the importance of full participation in society for out-groups, including where those out-groups are defined by religion, age or sexual orientation. How such duties are likely to look in practice will of course vary from public authority to public authority, and there may well be some variation as between different equality grounds. However, a common thread between different grounds should still be able to be seen, with the public sector duty being used across the public sector to create an 'equal society [which] protects and promotes equal, real freedom and substantive opportunity to live in the ways people value and would choose, so that everyone can flourish' (Equalities Review, 2007).

\section{References:}

Bardasi and Jenkins Income in later life: Work history matters by published for the Joseph Rowntree Foundation (2002).

Barmes, Equality Law and Experimentation: The Positive Action Challenge (2009) 68 CLJ 623

Barnard and Hepple, 'Substantive Equality' (2000) 59 CLJ 562

Collins 'Discrimination, Equality and Social Inclusion' (2003) 66 MLR 16, S 
Fairness and Freedom: the final report of the Equalities Review, February 2007. http://archive.cabinetoffice.gov.uk/equalitiesreview/upload/assets/www.t heequalitiesreview.org.uk/equality review.pdf (accessed 24th June 2010). Fraser, 'Rethinking Recognition' (2000) 3 New Left Review 107 Fraser, From Redistribution to Recognition? Dilemmas of Justice in a 'PostSocialist' Age (1995) New Left Review 1/212 68

Fredman, Discrimination Law (Oxford, OUP, 2002),

Fredman, The Age of Equality in Fredman and Spencer, Age as an Equality Issue: Legal and Policy Perspectives (Oxford, Hart Publishing, 2003).

Fredman, The Future of Equality In Britain, EOC, Working Paper Series No. 5, (London, Equal Opportunities Commission 2002) 11, N Fraser, 'Rethinking Recognition' (2000) 3 New Left Review 107.

Hepple, 'The Aims of Equality Law' in O'Cinneide and Holder (eds) Current Legal Problems (2008, OUP, Oxford).

Kant, The Moral Law: Kant's Groundwork of the Metaphysics of Morals (trans HJ Paton) London, Hutchinson 1963).

Kersley, Alpin, Forth, Bryson, Bewley, Dix, Oxenbridge Inside the Workplace: First Findings from the 2004 Workplace Employment Relations Survey (2004) (http://webarchive.nationalarchives.gov.uk/+/http://www.dti.gov.uk/er/emar/wer s5.htm\#5 accessed 21 December 2010)

Lester and Uccellari 'Extending the equality duty to religion, conscience and belief: Proceed with caution' [2008] EHRLR 567.

Lulham, Transport for London's Approach to Equality and Supplier Diversity through Procurement, (2011) IJDL

Manfredi andVickers, Retirement and Age Discrimination: Managing Retirement in Higher Education (2009) ILJ 343-364.

Manfredi, Developing Good Practice in Managing Age Diversity in the Higher Education Sector: An Evidence-Based Approach (2008, Centre for Diversity Policy Research and Practice, Oxford Brookes University, ISBN 978-1873576-77-9)

McColgan, 'Class wars? Religion and (In)equality in the Workplace' (2009) 38 ILJ 1.

McCrudden 'Thinking about the discrimination directives' (2005) 1 European Anti-Discrimination Law Review 17.

Moon and Allen, 'Dignity Discourse In Discrimination Law: A Better Route To Equality' (2006) EHRLR 610.

O'Cinneide, 'Fumbling Towards Coherence: The Slow Evolution of Equality and Anti-Discrimination Law in Britain' (2006) NILQ 57

Okin, (1998) 'Feminism and Multiculturalism' 108 Ethics 661, cited by Malik, From Conflict to Cohesion', p 17.

Stewart, The Expanded Public Sector Duty: Age, Religion and Sexual Orientation - A Practitioner's View (2011) IJDL

Taylor, Multiculturalism and 'The Politics of Recognition (1992, Princeton University Press, Princeton).

Vickers, 'Promoting Equality or Fostering Restentment' (2011) Legal Studies (Forthcoming).

Westen, 'The Empty Idea of Equality' (1982) 95 Harv. L.R. 537 
